\title{
Insulin Resistance of Glucose Uptake in Skeletal Muscle Cannot Be Ameliorated by Enhancing Endothelium-dependent Blood Flow in Obesity
}

\author{
Hanna Laine,, Hannele Yki-Järvinen," Olli Kirvelä,§ Tuula Tolvanen, ${ }^{\star}$ Maria Raitakari, ${ }^{\star}$ Olof Solin, ${ }^{\star}$ Merja Haaparanta, \\ Juhani Knuuti, ${ }^{\star}$ and Pirjo Nuutila ${ }^{\ddagger}$ \\ *Turku PET Centre, ${ }^{\ddagger}$ Department of Medicine and ${ }^{\S}$ Department of Anesthesiology, University of Turku, Turku, Finland; and ${ }^{\|}$Department \\ of Medicine, Division of Endocrinology, University of Helsinki, Helsinki, Finland
}

\begin{abstract}
We tested the hypothesis that endothelium-dependent vasodilatation is a determinant of insulin resistance of skeletal muscle glucose uptake in human obesity. Eight obese (age $26 \pm 1 \mathrm{yr}$, body mass index $37 \pm 1 \mathrm{~kg} / \mathrm{m}^{2}$ ) and seven nonobese males $\left(25 \pm 2 \mathrm{yr}, 23 \pm 1 \mathrm{~kg} / \mathrm{m}^{2}\right)$ received an infusion of bradykinin into the femoral artery of one leg under intravenously maintained normoglycemic hyperinsulinemic conditions. Blood flow was measured simultaneously in the bradykinin and insulin- and the insulin-infused leg before and during hyperinsulinemia using $\left[{ }^{15} \mathrm{O}\right]$-labeled water $\left(\left[{ }^{15} \mathrm{O}\right] \mathrm{H}_{2} \mathrm{O}\right)$ and positron emission tomography (PET). Glucose uptake was quantitated immediately thereafter in both legs using $\left[{ }^{18} \mathrm{~F}\right]-$ fluoro-deoxy-glucose ( $\left.\left[{ }^{18} \mathrm{~F}\right] \mathrm{FDG}\right)$ and PET. Whole body insulin-stimulated glucose uptake was lower in the obese $\left(507 \pm 47 \mu \mathrm{mol} / \mathrm{m}^{2} \cdot \mathrm{min}\right)$ than the nonobese $(1205 \pm 97$ $\left.\mu \mathrm{mol} / \mathrm{m}^{2} \cdot \min , P<0.001\right)$ subjects. Muscle glucose uptake in the insulin-infused leg was $66 \%$ lower in the obese $(19 \pm 4$ $\mu \mathrm{mol} / \mathrm{kg}$ muscle $\cdot \mathrm{min})$ than in the nonobese $(56 \pm 9 \mu \mathrm{mol} / \mathrm{kg}$ muscle $\cdot \min , P<0.005)$ subjects. Bradykinin increased blood flow during hyperinsulinemia in the obese subjects by $75 \%$ from $16 \pm 1$ to $28 \pm 4 \mathrm{ml} / \mathrm{kg}$ muscle $\cdot \min (P<0.05)$, and in the normal subjects by $65 \%$ from $23 \pm 3$ to $38 \pm 9 \mathrm{ml} / \mathrm{kg}$ muscle $\cdot \min (P<0.05)$. However, this flow increase required twice as much bradykinin in the obese $(51 \pm 3 \mu \mathrm{g}$ over $100 \mathrm{~min})$ than in the normal $(25 \pm 1 \mu \mathrm{g}, P<0.001)$ subjects. In the obese subjects, blood flow in the bradykinin and insulin-infused leg $(28 \pm 4 \mathrm{ml} / \mathrm{kg}$ muscle $\cdot \min )$ was comparable to that in the insulin-infused leg in the normal subjects during hyperinsulinemia $(24 \pm 5 \mathrm{ml} / \mathrm{kg}$ muscle $\cdot \min )$. Despite this, insulin-stimulated glucose uptake remained unchanged in the bradykinin and insulin-infused leg $(18 \pm 4$ $\mu \mathrm{mol} / \mathrm{kg} \cdot \min )$ compared with the insulin-infused leg $(19 \pm 4 \mu \mathrm{mol} / \mathrm{kg}$ muscle $\cdot \min )$ in the obese subjects. Insulinstimulated glucose uptake also was unaffected by bradykinin in the normal subjects $(58 \pm 10 \mathrm{vs} .56 \pm 9 \mu \mathrm{mol} / \mathrm{kg} \cdot \mathrm{min}$, bradykinin and insulin versus insulin leg). These data demonstrate that obesity is characterized by two distinct defects
\end{abstract}

Address correspondence to Hanna Laine, M.D., Department of Medicine, University of Turku, FIN-20520 Turku, Finland. Phone: 358-22611-611; FAX: 358-2-2612-030; E-mail: hannal@pet.tyks.fi

Received for publication 30 June 1997 and accepted in revised form 18 December 1997.

J. Clin. Invest.

(C) The American Society for Clinical Investigation, Inc. 0021-9738/98/03/1156/07 \$2.00

Volume 101, Number 5, March 1998, 1156-1162

http://www.jci.org in skeletal muscle: insulin resistance of cellular glucose extraction and impaired endothelium-dependent vasodilatation. Since a $75 \%$ increase in blood flow does not alter glucose uptake, insulin resistance in obesity cannot be overcome by normalizing muscle blood flow. (J. Clin. Invest. 1998. 101: 1156-1162.) Key words: obesity • blood flow • insulin resistance $\bullet$ bradykinin $\bullet$ positron emission tomography

\section{Introduction}

Obesity is a major cause of insulin resistance in humans (1). This resistance is characterized by an inability of insulin to normally increase glucose uptake in leg tissues and involves a defect in cellular glucose extraction $(2,3)$. In addition to this classic defect in insulin action, the ability of insulin to vasodilate has also been examined in a few studies and has been found to be either blunted $(2,4)$ or normal $(5)$ in obese subjects. Insulin-induced vasodilatation can be abolished by inhibiting nitric oxide $(\mathrm{NO})^{1}$ synthesis $(6,7)$. Resistance to insulin's ability to augment blood flow responses to endothelium-dependent vasodilators was also demonstrated recently in obese subjects (4). Such impaired vasodilatation has been suggested to contribute to glucose delivery. Baron et al. reported enhancement of glucose uptake by methacholine in normal subjects, and a decrease in glucose uptake by $\mathrm{L}-\mathrm{N}$-monomethylarginine (L-NMMA), a vasoconstrictor and an inhibitor of NO synthesis $(8,9)$. However, interpretation of these data is complicated, since the neuronal (nNOS) (10) isoform of NO synthase (NOS) is expressed in myocytes and skeletal muscle, and NOS inhibition by L-NMMA inhibits glucose transport in incubated skeletal muscle preparations (11). In addition, sodium nitroprusside, an NO donor, has been found recently to increase glucose transport both in the absence and presence of insulin rat extensor digitorum longus muscles in vitro (12). In contrast to these findings, blood flow increases induced with agents such as adenosine (13) or bradykinin (14) do not enhance glucose uptake in vivo in normal subjects. Whether stimulation of blood flow with such agents would increase glucose uptake in skeletal muscle of insulin-resistant obese subjects is unknown. If so, this would provide a rationale for the design of vasodilatory drugs for treatment of both insulin resistance of glucose uptake and endothelial dysfunction. Bradykinin is an endothelium-dependent vasodilator (15), which increases forearm blood flow in a dose- and NO synthesis-dependent fashion in humans (16). However, it does not stimulate glucose transport, glycolysis, or glycogen synthesis in isolated rat soleus muscle

1. Abbreviations used in this paper: $\mathrm{AV}$, arteriovenous; $\left[{ }^{18} \mathrm{~F}\right] \mathrm{FDG}$, $\left[{ }^{18} \mathrm{~F}\right]$-fluoro-deoxy-glucose; L-NMMA, L- $N$-monomethylarginine; nNOS, neuronal isoform of NO synthase; NO, nitric oxide; PET, positron emission tomography. 
(17), cardiac myocytes, or in the perfused rat heart (18). Whether this is because of rapid degradation of bradykinin by angiotensin-converting enzyme or other mechanisms (19) is unclear. In this study, we quantitated rates of insulin-stimulated glucose uptake directly in muscle tissue and used bradykinin to examine whether enhancement of blood flow in femoral muscle augments insulin-stimulated glucose uptake in obesity. To this end, we infused bradykinin into the femoral artery and measured blood flow as well as glucose uptake simultaneously in both legs under normoglycemic hyperinsulinemic conditions using positron emission tomography (PET) techniques. This allowed analysis of the effect of increasing blood flow on insulin-stimulated glucose uptake directly in skeletal muscle in vivo.

\section{Methods}

\section{Subjects}

Eight obese men (age $26 \pm 1 \mathrm{yr}$, weight $121 \pm 4 \mathrm{~kg}$, height $181 \pm 2 \mathrm{~cm}$, body mass index $37 \pm 1 \mathrm{~kg} / \mathrm{m}^{2}$, range $31-42 \mathrm{~kg} / \mathrm{m}^{2}$, serum cholesterol $3.9 \pm 0.1$, LDL-cholesterol $2.3 \pm 0.1$, HDL-cholesterol $0.9 \pm 0.1$, triglycerides $1.5 \pm 0.1 \mathrm{mmol} / \mathrm{liter}$ ) volunteered for the study. The subjects were healthy as judged by history and physical examination, were not taking any medications, and had no family history of diabetes. All subjects were normotensive and had normal glucose tolerance, blood counts, electrolytes, and normal renal and liver function tests. The results of this study group were compared with results of seven normal men (age $25 \pm 2 \mathrm{yr}$, weight $73 \pm 3 \mathrm{~kg}$, height $180 \pm 2 \mathrm{~cm}$, body mass index $23 \pm 1 \mathrm{~kg} / \mathrm{m}^{2}$, serum cholesterol $4.0 \pm 0.2$, LDL-cholesterol $2.5 \pm 0.1$, HDL-cholesterol $1.0 \pm 0.1$, triglycerides $1.1 \pm 0.2 \mathrm{mmol} /$ liter, $P<0.005$ for weight and body mass index, NS for other parameters for nonobese versus obese subjects). Data on the nonobese subjects have been reported previously (14). The nature, purpose, and potential risks of the study were explained to all subjects before they gave their written informed consent to participate. The study was approved by the Ethical Committee of the Turku University Hospital.

\section{Study design}

All studies were performed after a 10-12-h overnight fast. The subjects were lying supine during the study. Three catheters were inserted, one in an antecubital vein for infusions of glucose and insulin and injections of $\left[{ }^{15} \mathrm{O}\right] \mathrm{H}_{2} \mathrm{O}$ and $\left[{ }^{18} \mathrm{~F}\right] \mathrm{FDG}$, another in the opposite radial artery for blood sampling, and a third in the femoral artery for infusion of bradykinin (Hoechst, Frankfurt, Germany). The study for each subject consisted of a 30-min basal period ( -30 to $0 \mathrm{~min}$ ) and a 100min normoglycemic hyperinsulinemic period $(0-100 \mathrm{~min})$ during which bradykinin was infused into the other leg (Fig. 1). Blood flow was measured in both legs using $\left[{ }^{15} \mathrm{O}_{3} \mathrm{H}_{2} \mathrm{O}\right.$ during the 30 -min basal period before start of the insulin and bradykinin infusions. At $0 \mathrm{~min}$, an intravenous infusion of insulin $(1 \mathrm{mU} / \mathrm{kg} \cdot \mathrm{min})$ and an intraarterial infusion of bradykinin were started simultaneously and continued for $100 \mathrm{~min}$. Administration of insulin per kilogram of body weight rather than body surface area results in significantly higher insulin concentrations in obese than in nonobese subjects, because the relative distribution space of insulin is lower in obese than in nonobese subjects (20). This approach was chosen to maintain the protocol identical to that used in the nonobese subjects (14). The goal was to increase blood flow by $\sim 50 \%$ in both groups. Preliminary studies in two obese subjects (body mass indexes 39 and $40 \mathrm{~kg} / \mathrm{m}^{2}$ ) showed that a $35-\mu \mathrm{g}$ bradykinin dose had no (16 vs. $16 \mathrm{ml} / \mathrm{kg}$ muscle $\cdot$ min, insulin-infused vs. bradykinin and insulin-infused leg) or only a slight (17 vs. $21 \mathrm{ml} / \mathrm{kg}$ muscle $\cdot \min$ ) effect on muscle blood flow. Therefore, the total dose of bradykinin required to increase blood flow by $\sim 50 \%$ was significantly higher in the obese than the nonobese subjects (see Results). At $50 \mathrm{~min}$, measurement of muscle blood flow was repeated using $\left[{ }^{15} \mathrm{O}\right] \mathrm{H}_{2} \mathrm{O}$ and PET (Fig. 1). Femoral muscle glucose uptake was

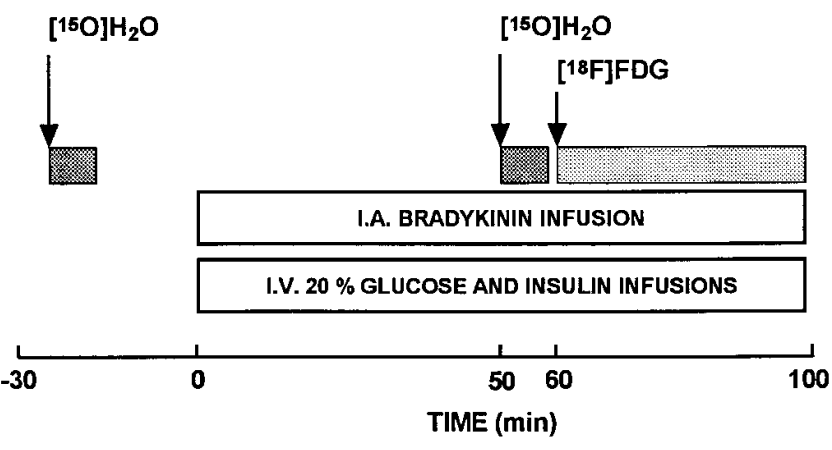

Figure 1. Design of the study. Bradykinin was infused intraarterially (I.A.) during intravenously (I.V.) maintained normoglycemic hyperinsulinemic (insulin infusion rate $1 \mathrm{mU} / \mathrm{kg} \cdot \mathrm{min}$ ) conditions. The arrows indicate the time of intravenous injections of the positron emitting tracers $\left[{ }^{15} \mathrm{O}\right] \mathrm{H}_{2} \mathrm{O}$ and $\left[{ }^{18} \mathrm{~F}\right] \mathrm{FDG}$. After the injections, a dynamic scan of both femoral regions (hatched rectangles) was obtained to quantitate blood flow and glucose uptake simultaneously in both legs.

measured immediately thereafter using $\left[{ }^{18} \mathrm{~F}\right] \mathrm{FDG}$ and PET (Fig. 1). Blood pressure (Hem-705C oscillometric blood pressure monitor; Omron Corp., Tokyo, Japan) and heart rate were recorded basally and every 15-30 min during the insulin and bradykinin infusions. Blood samples for the measurement of serum insulin concentrations were taken as detailed below.

\section{Measurement of muscle blood flow and glucose uptake with PET}

Production of $\left[{ }^{15} \mathrm{O}\right] \mathrm{H}_{2} \mathrm{O}$ and $\left[{ }^{18} \mathrm{~F}\right] F D G$. For production of $\left[{ }^{15} \mathrm{O}\right]$ compounds, a low-energy deuteron accelerator was used (Cyclone 3; Ion Beam Application Inc., Louvain-la-Neuve, Belgium). $\left[{ }^{15} \mathrm{O}^{-} \mathrm{H}_{2} \mathrm{O}\right.$ was produced using a dialysis technique in a continuously working water module (21). Sterility and pyrogen tests were performed daily to verify the purity of the product. $\left[{ }^{15} \mathrm{O}\right]$ Oxygen was processed to $\left[{ }^{15} \mathrm{O}\right] \mathrm{CO}$ in a charcoal oven at $950^{\circ} \mathrm{C}$. Gas chromatographic analysis was performed to verify the purity of the product before each study. $\left[{ }^{18} \mathrm{~F}\right] \mathrm{FDG}$ was synthesized with an automatic apparatus as described by Hamacher et al. (22). The specific radioactivity at the end of the synthesis was $2 \mathrm{Ci} / \mu \mathrm{mol}$ and the radiochemical purity exceeded $98 \%$.

Image acquisition and processing. An eight-ring ECAT 931/08 tomograph (Siemens/CTI Corp., Knoxville, TN) was used. The scanner has an axial resolution of $6.7 \mathrm{~mm}$ and in plane resolution of 6.5 $\mathrm{mm}$. The images were obtained from the femoral regions. Before emission scanning, a transmission scan for correction of photon attenuation was performed for $10 \mathrm{~min}$ with a removable ring source containing ${ }^{68} \mathrm{Ge}$.

For the flow studies, $\left[{ }^{15} \mathrm{O}\right] \mathrm{H}_{2} \mathrm{O}(30-45 \mathrm{mCi})$ was infused intravenously (30 s) and a dynamic scan, for $6 \mathrm{~min}$, was started simultaneously. To obtain the input function, arterial blood was withdrawn with a pump at a speed of $6 \mathrm{ml} / \mathrm{min}$ from the radial artery, and the radioactivity concentration was measured using a two-channel detector system (Scanditronix, Uppsala, Sweden), which was calibrated to an automated gamma-counter (1480 Wizard; Wallac Inc., Turku, Finland) and the PET scanner.

To obtain the actual input function for the tissue element, internal dispersion from the arterial line and external dispersion from the tubing in the blood sampling system were corrected for by using an exponential dispersion function with an internal dispersion time constant of $5 \mathrm{~s}$ (23). For the external dispersion time constant, a measured value of $3 \mathrm{~s}$ was used. The delay between the input curve and the tissue curve was solved by fitting (23).

For the $\left[{ }^{18} \mathrm{~F}\right] \mathrm{FDG}$ study, $4-9 \mathrm{mCi}$ of $\left[{ }^{18} \mathrm{~F}\right] \mathrm{FDG}\left(t_{1 / 2} 109 \mathrm{~min}\right)$ was injected intravenously over $2 \mathrm{~min}$ and dynamic scanning for $40 \mathrm{~min}$ 
was started $(12 \times 15 \mathrm{~s}, 4 \times 30 \mathrm{~s}, 3 \times 60 \mathrm{~s}, 1 \times 120 \mathrm{~s}, 6 \times 300 \mathrm{~s})$. Blood samples for measurement of plasma radioactivity were withdrawn during dynamic scanning (approximately one sample from one time frame). Radioactivity of the plasma samples was measured in the well counter and cross-calibrated with the PET scanner. All data were corrected for dead-time, decay, and measured photon attenuation as described previously and reconstructed into a $128 \times 128$ matrix (24).

Calculation of blood flow. The methods to measure blood flow with $\left[{ }^{15} \mathrm{O}_{3} \mathrm{H}_{2} \mathrm{O}\right.$ and PET are based on the principle of inert gas exchange between blood and tissues developed by Kety (25). We used the autoradiographic method to calculate the blood flow pixel by pixel with a 200-s integration time and dispersion and delay corrected arterial input curve $(23,26,27)$. The partition coefficient for water in muscle tissue was assumed to be $0.95 \mathrm{ml} / \mathrm{g}$ in the calculation. The method to measure blood flow in muscle with $\left[{ }^{15} \mathrm{O}\right] \mathrm{H}_{2} \mathrm{O}$ and PET has been validated recently (27).

Regions of interest were drawn in the posterior, anterolateral, and anteromedial muscular compartments of the femoral region in four slices in both legs. Large vessels were avoided when outlining the muscle areas. The localization of the muscle compartments was verified by comparison of the flow images with the transmission image, which provides a topographical distribution of tissue density. The regions of interest outlined in the flow images were copied to the FDG images to obtain quantitative data from identical regions.

Calculation of regional glucose uptake. The three-compartment model of $\left[{ }^{18} \mathrm{~F}\right]$ FDG kinetics was used as described previously $(24,28$, 29). Plasma and tissue time-activity curves were analyzed graphically to quantitate the fractional rate of tracer phosphorylation $K_{\mathrm{i}}(24,29$, 30 ). A minimum of six points was used to determine the slope by linear regression. The rate of the glucose uptake $(r G U)$ is obtained by multiplying $K_{\mathrm{i}}$ by the plasma glucose concentration [Glc] divided by a lumped constant term (LC): $\left.r G U=[G l c]_{\mathrm{p}} / \mathrm{LC}\right) \times K_{\mathrm{i}}$. The lumped constant accounts for differences in the transport and phosphorylation of $\left[{ }^{18} \mathrm{~F}\right] \mathrm{FDG}$ and glucose. A lumped constant value of 1.0 for skeletal muscle was used as previously described (24). Glucose extraction (arteriovenous $[\mathrm{AV}]$ difference) was calculated using the Fick equation by dividing muscle glucose uptake by muscle blood flow.

\section{Whole body glucose uptake}

Whole body glucose uptake was determined, independent of the PET measurements, using the euglycemic hyperinsulinemic clamp technique, as described previously $(24,31)$. During hyperinsulinemia, normoglycemia was maintained using a variable rate infusion of $20 \%$ glucose based on arterial plasma glucose measurements (32). The rate of glucose uptake was calculated during the time period when the measurements of blood flow and muscle glucose uptake were performed (50-100 min). Serum insulin concentrations were measured basally and at 30-min intervals during the insulin infusion (33). Whole body glucose uptake was expressed per body surface area since glucose uptake rates expressed per body surface area are better correlated to rates expressed per fat free mass than those expressed per body weight (34).

\section{Statistical procedures}

Statistical comparisons between measurements performed in the basal state and during hyperinsulinemia were performed using the nonparametric Wilcoxon's signed rank test and comparisons between obese and nonobese groups were performed using the nonparametric Wilcoxon rank sum test (= Mann-Whitney U test) for independent samples. Correlations between selected study variables were calculated using Spearman's rank correlation coefficient. Data are expressed as mean $\pm \mathrm{SEM}$.

\section{Results}

Glucose and insulin concentrations. Plasma glucose concentrations were similar in the obese and nonobese subjects basally

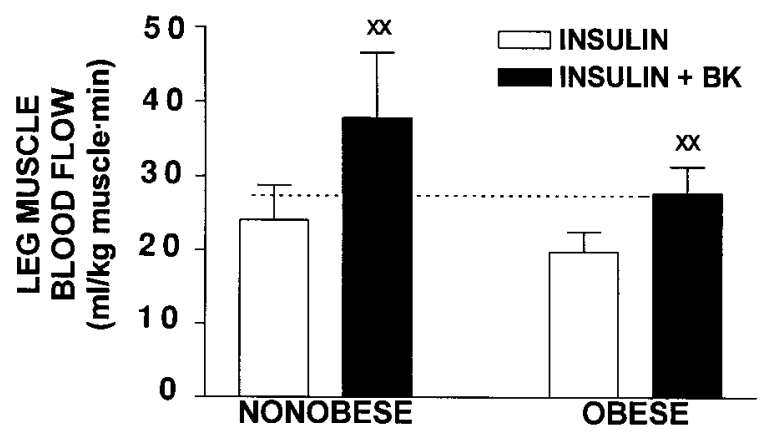

Figure 2. Rates (mean \pm SE) of blood flow in skeletal muscles of the femoral region under normoglycemic hyperinsulinemic conditions in the insulin and bradykinin-infused (INSULIN $+B K)$ and in the insulin-infused (INSULIN) leg of obese and nonobese subjects. ${ }^{x x} P<$ 0.01 for comparison of flow in INSULIN + BK vs. INSULIN leg.

(5.8 \pm 0.2 vs. $5.9 \pm 0.1 \mathrm{mmol} / \mathrm{liter})$ and during hyperinsulinemia $(5.3 \pm 0.1$ vs. $5.2 \pm 0.1 \mathrm{mmol} / \mathrm{liter})$. Fasting insulin concentrations were higher in the obese $(15 \pm 3 \mathrm{mU} / \mathrm{liter})$ than in the nonobese $(6 \pm 1 \mathrm{mU} /$ liter, $P<0.005)$ subjects. During hyperinsulinemia, serum insulin concentrations were slightly higher in the obese $(79 \pm 4 \mathrm{mU} /$ liter $)$ than in the nonobese $(62 \pm 1 \mathrm{mU} / \mathrm{li}-$ ter, $P<0.01)$ subjects.

Whole body and femoral muscle glucose uptake. Whole body glucose uptake, expressed per surface area, was 58\% lower in the obese $\left(507 \pm 47 \mu \mathrm{mol} / \mathrm{m}^{2} \cdot \mathrm{min}\right)$ than the nonobese $\left(1205 \pm 97 \mu \mathrm{mol} / \mathrm{m}^{2} \cdot \min , P<0.001\right)$ subjects. When expressed per kilogram of body weight, insulin-stimulated whole body glucose uptake averaged $10 \pm 1 \mu \mathrm{mol} / \mathrm{kg} \cdot \min$ in the obese and $32 \pm 3 \mu \mathrm{mol} / \mathrm{kg} \cdot \mathrm{min}$ in the nonobese subjects $(P<0.005)$. Femoral muscle glucose uptake in the insulin-infused leg was $66 \%$ lower in the obese $(19 \pm 4 \mu \mathrm{mol} / \mathrm{kg}$ muscle $\cdot \min )$ than in the nonobese $(56 \pm 9 \mu \mathrm{mol} / \mathrm{kg}$ muscle $\cdot \min , P<0.005)$ subjects.

Effect of bradykinin on muscle blood flow and glucose uptake. Muscle blood flows were similar in both legs before bradykinin and insulin infusions in the obese subjects $(16 \pm 1$ vs. $15 \pm 1 \mathrm{ml} / \mathrm{kg}$ muscle $\cdot \min$, bradykinin and insulin-infused vs. insulin-infused vs. control leg, NS), and the nonobese subjects ( $23 \pm 3$ vs. $21 \pm 3 \mathrm{ml} / \mathrm{kg}$ muscle $\cdot \min$, respectively), and not significantly different between the groups.

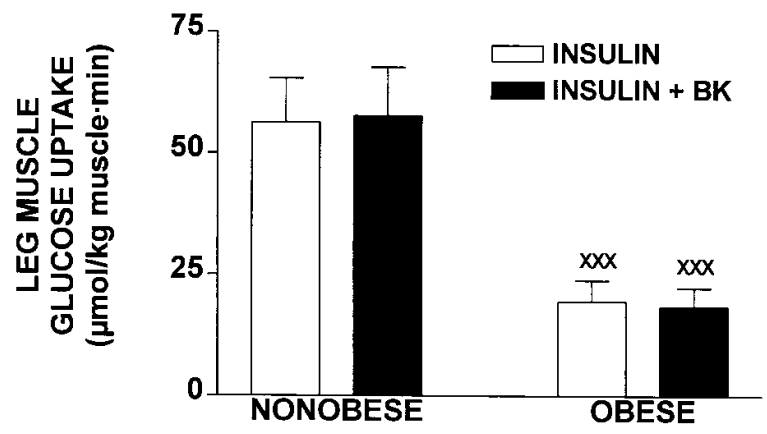

Figure 3. Rates of glucose uptake in skeletal muscles of the femoral region under normoglycemic hyperinsulinemic conditions in the insulin and bradykinin-infused (INSULIN $+B K)$ and in the insulininfused (INSULIN) leg of obese and nonobese subjects. ${ }^{x x x} P<0.01$ for comparison of obese vs. nonobese subjects. 
Bradykinin increased blood flow in the obese subjects by $75 \%$ from $16 \pm 1$ (basal flow) to $28 \pm 4 \mathrm{ml} / \mathrm{kg}$ muscle $\cdot \min (P<$ 0.05 ), and in the normal subjects by $65 \%$ from $23 \pm 3$ (basal flow) to $38 \pm 9 \mathrm{ml} / \mathrm{kg}$ muscle $\cdot \min (P<0.05)$. However, this flow increase required twice as much bradykinin in the obese $(51 \pm 3 \mu \mathrm{g}$ over $100 \mathrm{~min})$ than in the normal subjects $(25 \pm 1 \mu \mathrm{g}$, $P<0.001)$. Basal flow was significantly correlated with flow during bradykinin and insulin infusions both in the obese $(r=$ $0.80, P<0.02)$ and the nonobese $(r=0.79, P<0.05)$ subjects. In the obese subjects, blood flow in the bradykinin and insulin-infused leg was comparable to that in the insulin-infused leg in the normal subjects during hyperinsulinemia $(24 \pm 5 \mathrm{ml} /$ $\mathrm{kg}$ muscle $\cdot \min$, Fig. 2). Insulin per se did not increase blood flow in the nonobese ( $21 \pm 3$ vs. $24 \pm 5 \mathrm{ml} / \mathrm{kg}$ muscle $\cdot \min , \mathrm{NS})$ or the obese $(15 \pm 1 \mathrm{vs} .19 \pm 3 \mathrm{ml} / \mathrm{kg}$ muscle $\cdot \min , \mathrm{NS})$ subjects.

Glucose uptake remained unchanged in the bradykinin and insulin-infused leg $(18 \pm 4 \mu \mathrm{mol} / \mathrm{kg} \cdot \min )$ compared with the insulin-infused leg $(19 \pm 4 \mu \mathrm{mol} / \mathrm{kg}$ muscle $\cdot \min )$ in the obese subjects. Glucose uptake also remained unchanged in the normal subjects $(58 \pm 10$ vs. $56 \pm 9 \mu \mathrm{mol} / \mathrm{kg} \cdot \mathrm{min}$, bradykinin and insulin-infused vs. insulin-infused leg, Fig. 3). Examples of flow and glucose uptake images are shown in Fig. 4. Rates of glucose uptake in the insulin-infused and insulin and bradykinin-infused leg were significantly correlated within both the obese $(r=0.96, P<0.001)$ and the nonobese $(r=0.91, P<$ 0.01 ) subjects with no difference between either slopes or intercepts of this relationship between the obese or nonobese subjects (Fig. 5).

Glucose extraction. In the obese group glucose extraction was significantly lower during hyperinsulinemia both in the in-

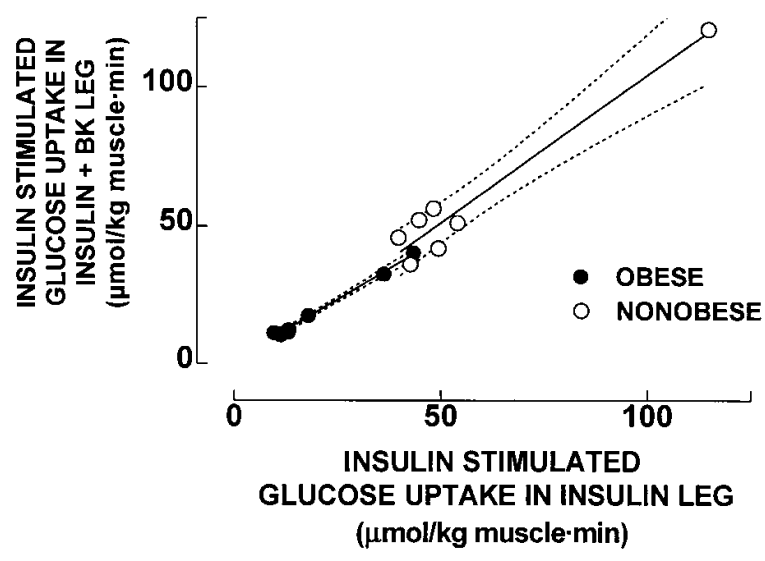

Figure 5. The relationship between glucose uptake in the insulininfused leg and in the insulin and bradykinin-infused leg in the obese (filled circles) and nonobese (open circles) subjects.

sulin-infused leg $(0.9 \pm 0.1$ vs. $2.5 \pm 0.2 \mathrm{mmol} /$ liter, obese vs. nonobese subjects, $P<0.005)$ and in the bradykinin and insulin-infused leg $(0.7 \pm 0.1$ vs. $1.7 \pm 0.2 \mathrm{mmol} /$ liter, respectively, $P<0.005)$ compared with the nonobese subjects. The bradykinin-induced increase in blood flow was accompanied by a significant decrease in glucose extraction in the bradykinin-infused leg in both the obese $(0.7 \pm 0.1$ vs. $0.9 \pm 0.1 \mathrm{mmol} / \mathrm{liter}$, bradykinin and insulin-infused vs. insulin-infused leg, $P<0.05)$ and the nonobese $(1.7 \pm 0.2$ vs. $2.5 \pm 0.2 \mathrm{mmol} / \mathrm{liter}$, respectively, $P<0.01)$ subjects.

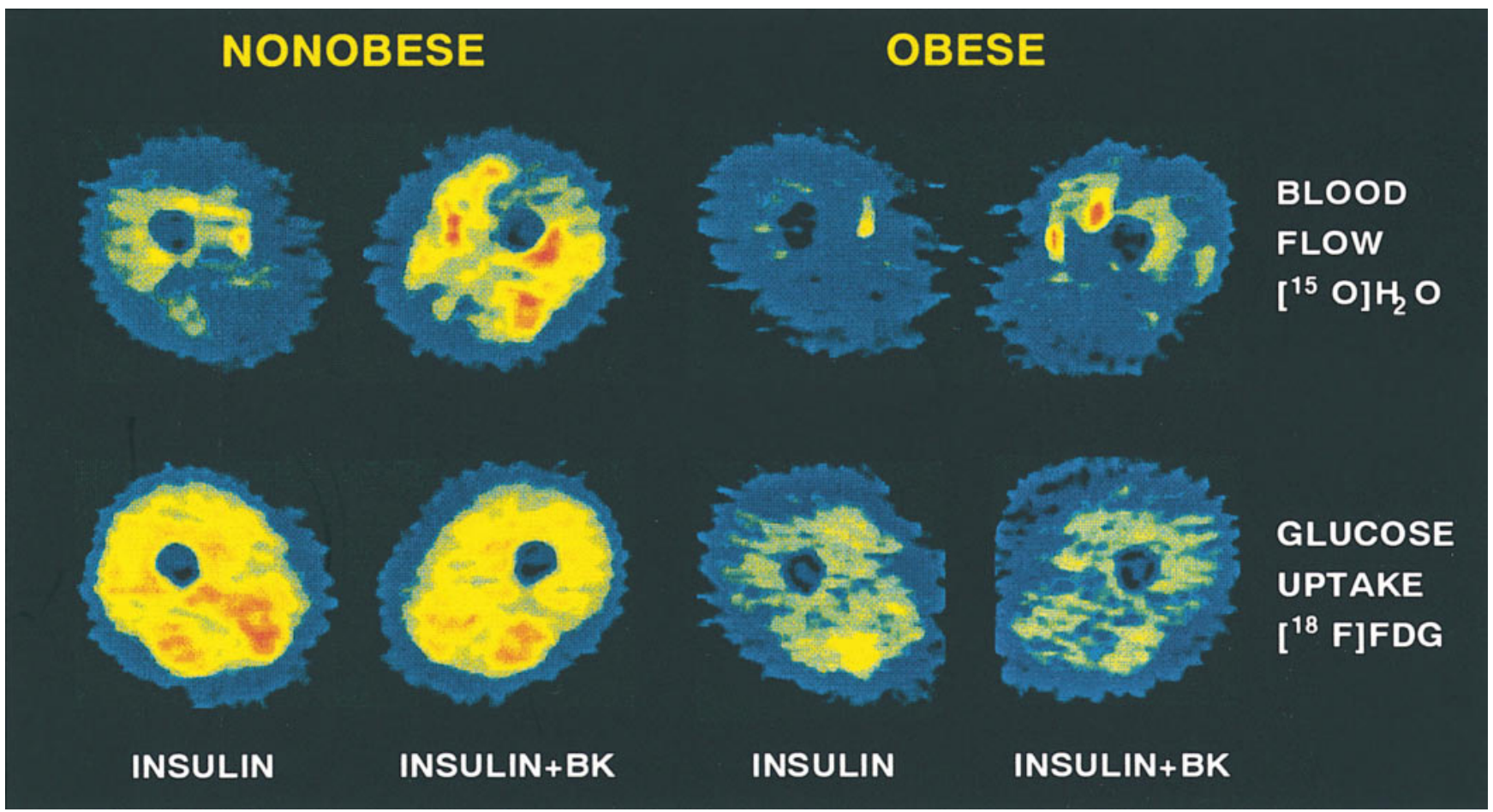

Figure 4. Cross-sectional images of blood flow and glucose uptake in the femoral region of an obese and a nonobese subject during insulin stimulation as seen during PET scanning. The top shows parametric flow images obtained using $\left[{ }^{15} \mathrm{O}^{-} \mathrm{H}_{2} \mathrm{O}\right.$ and PET, and the bottom shows glucose uptake measured with $\left[{ }^{18} \mathrm{~F}\right] \mathrm{FDG}$ and PET. The insulin and bradykinin-infused leg $(I N S U L I N+B K)$ is shown on the right and the insulininfused (INSULIN) leg on the left. 


\section{Discussion}

The present data demonstrate two defects in skeletal muscle of obese subjects: a defect in insulin-stimulated cellular glucose extraction, and, a defect in endothelium-dependent vasodilatation. Furthermore, we found that a $75 \%$ increase in femoral blood flow by bradykinin had no effect on insulin-stimulated glucose uptake. These data demonstrate that correction of one defect does not influence the other, and thus that glucose uptake is not limited by substrate delivery in obesity.

Limb blood flow responses to insulin have been examined sparsely in obese subjects. Laakso et al. (35) infused insulin sequentially in doses ranging from 40 to $1,200 \mathrm{mU} / \mathrm{m}^{2} \cdot \min$ for over $6.5 \mathrm{~h}$ and found blunted blood flow responses to insulin in obese subjects. Mandarino et al. (5) found no increase in blood flow in either normal or obese subjects during a $3-\mathrm{h} 40 \mathrm{mU} / \mathrm{m}^{2}$. min insulin infusion. However, these seemingly discrepant results can be readily explained by considering the differences in the dose and duration of the insulin infusions. In normal subjects, an insulin dose of $40 \mathrm{mU} / \mathrm{m}^{2} \cdot$ min increases glucose extraction 10-20-fold within $30 \mathrm{~min}(35,36)$. During this time period, blood flow does not change significantly $(5,37-42)$. After the first 30-60 min, a time period during which insulin concentrations are physiological, glucose extraction remains constant (36) or increases slightly (35), while blood flow increases continuously, and up to twofold within $6 \mathrm{~h}$ compared with baseline values. In this study the insulin dose was $40 \mathrm{mU} / \mathrm{m}^{2} \cdot \min$ and the measurement of blood flow was performed at $50 \mathrm{~min}$. Under these conditions, we observed no significant difference in insulin-stimulated blood flows between obese and nonobese subjects, and no stimulation of blood flow by insulin. This result is entirely consistent with the previous data reviewed above, and indicates that defects in insulin-induced vasodilatation are not responsible for insulin resistance under physiological conditions. These data do not exclude defects in insulin's hemodynamic effects at higher insulin concentrations or after more prolonged infusions of insulin than those used in this study. Indeed, given that insulin and bradykinin share an NO synthesis-dependent mechanism of action, one would expect to find defects in insulin-induced vasodilatation under conditions where the stimulus is potent enough to clearly stimulate blood flow. Of note, in this study blood flow was quantitated, for the first time, within skeletal muscle in the obese subjects, rather than in the entire limb. This approach avoids underestimation of blood flow because of difference in the limb fat content between obese and nonobese subjects.

Recently, blunted vasodilatory responses to methacholine but not sodium nitroprusside were found in obese subjects (4). In the latter study, identical doses of both drugs (micrograms per minute) were infused to both lean and obese subjects. The blood flow responses to methacholine were $\sim 50 \%$ reduced in the obese subjects. This degree of impairment is unlikely to be explained by a greater lean body mass in the obese subjects, since three times more methacholine was required to achieve comparable increases in blood flow in obese and nonobese subjects (4). The present study was not primarily designed to assess endothelial function, but we found that the dose of bradykinin which increased blood flow by $\sim 50 \%$ (25 $\mu \mathrm{g}$ over $100 \mathrm{~min}$ ) in normal subjects was insufficient to increase blood flow in the obese subjects by the same amount. We had to double the bradykinin dose to increase blood flow by the same absolute and relative amount as in the nonobese subjects. These data are consistent with endothelial dysfunction in obese subjects. Since bradykinin was infused under hyperinsulinemic conditions, this abnormality could be specific to bradykinin, or reflect an inability of insulin to potentiate bradykinin-induced vasodilatation, or both. Both defects may exist since Steinberg et al. found that both the ability of methacholine per se to vasodilate and the ability of insulin to potentiate methacholine induced vasodilatation were impaired in obese subjects (4). We also observed a close correlation between basal flow and flow in the bradykinin and insulin-infused leg in both the nonobese and obese subjects. This correlation is consistent with data demonstrating that a significant fraction of basal flow is endothelium dependent (43) and with the presence of subtle defects in endothelial function even basally in the obese as compared with the nonobese subjects.

Previous data regarding the effect of an increase in blood flow to enhance glucose uptake are controversial. In studies where either bradykinin (14) or adenosine (13) has been used to increase blood flow, insulin-stimulated glucose uptake has remained unchanged. We have also shown previously that bradykinin has no effect on glucose uptake when infused under basal conditions to normal subjects (14). In contrast, Buchanan et al. (44) reported that angiotensin II increases glucose uptake via a hemodynamic mechanism in normal subjects. However, in this study angiotensin II decreased renal plasma flow by $22-38 \%$ and insulin concentrations were significantly higher during angiotensin II than during saline infusion. Also, as glucose uptake increases as a function of time (36), it is possible that the increase in glucose uptake observed at the end of the insulin infusion when angiotensin II was coinfused with insulin was due to prolonged insulin exposure rather than angiotensin II. In keeping with this, local infusion of angiotensin II has no effect on insulin-stimulated glucose uptake in the forearm (45). When examining effects of flow alterations on glucose uptake, it is assumed that the vasoactive agent does not have flow-independent effects on glucose uptake. Recent studies have shown that nNOS is expressed in skeletal muscle (10), that NOS activity may be reduced in skeletal muscle of obese subjects (46), and that L-NMMA decreases glucose transport in isolated rat skeletal muscle preparations (12). These new data imply that conclusions from studies using L-NMMA (9) to modulate blood flow should be interpreted with caution. Taken together, modulation of blood flow by intraarterially administered agents, which themselves do not affect glucose uptake (adenosine, bradykinin, and angiotensin II) do not appear to change glucose uptake. The present data are consistent with these previous observations, and are the first to demonstrate that enhancement of blood flow in obese individuals with defects in both endotheliumdependent vasodilatation and insulin-stimulated glucose uptake does not augment glucose uptake.

In keeping with previous data, the obese subjects exhibited an $\sim 60 \%$ reduction in whole body glucose uptake, and also in femoral muscle glucose uptake compared with the nonobese subjects. Assuming that the nonobese males had $40 \%$ muscle of body weight (47), the measured muscle glucose uptake rate $(56 \mu \mathrm{mol} / \mathrm{kg} \cdot \operatorname{muscle} \cdot \min )$ accounted for $70 \%$ of total body glucose uptake, as measured using the clamp technique (32 $\mu \mathrm{mol} / \mathrm{kg} \cdot \mathrm{min})$. This estimate is in perfect agreement with previous estimates, obtained using the AV-balance technique, of the contribution of muscle tissue to whole body glucose uptake (47). 
When we calculated glucose AV differences across femoral muscle by dividing glucose uptake by blood flow, we found glucose extraction to be $64 \%$ lower in the obese than in the nonobese subjects. This result is consistent with previous data from in vivo studies $(3,5,35)$ demonstrating impaired cellular glucose utilization to be the major cause for insulin resistance in obesity. Studies performed in intact strips of human skeletal muscle have demonstrated decreased rates of glucose transport (48) and early defects in insulin signaling (impaired insulin receptor and IRS-1 phosphorylation and PI3-kinase activity) (49). Defects in transcapillary transport of insulin do not explain insulin resistance in obesity under steady-state conditions since obese subjects have markedly diminished glucose uptake rates despite having supranormal interstitial insulin concentrations (3).

The present data have implications for design of therapeutic strategies aimed at reducing the risk of cardiovascular disease in obese subjects. Although both hyperinsulinemia and endothelial dysfunction predispose to atherosclerosis (50-52), these abnormalities appear to be mechanistically unrelated and anatomically distinct. Therefore, it is unlikely that drugs which merely enhance blood flow and glucose or insulin delivery to the interstitial space will beneficially influence glucose homeostasis, while drugs such as the thiazolidinediones, which have insulinomimetic (53) and antioxidant actions $(54,55)$, could potentially correct both defects.

\section{Acknowledgments}

This work was supported by grants from the Academy of Finland $(\mathrm{H}$. Yki-Järvinen and P. Nuutila), the Sigrid Juselius (H. Yki-Järvinen) and Ahokas (H. Yki-Järvinen and P. Nuutila), Novo Nordisk (H. Yki-Järvinen and P. Nuutila), Ida Montin (H. Laine), and the Maud Kuistila (H. Laine) foundations.

\section{References}

1. DeFronzo, R.A., V. Soman, R. Sherwin, R. Hendler, and P. Felig. 1978. Insulin binding to monocytes and insulin action in human obesity, starvation and refeeding. J. Clin. Invest. 62:204-213.

2. Laakso, M., S.V. Edelman, J.M. Olefsky, G. Brechtel, P. Wallace, and A.D. Baron. 1990. Kinetics of in vivo muscle insulin-mediated glucose uptake in human obesity. Diabetes. 39:965-974.

3. Castillo, C., C. Bogardus, R. Bergman, P. Thuillez, and S. Lillioja. 1994. Interstitial insulin concentrations determine glucose uptake rates but not insulin resistance in lean and obese men. J. Clin. Invest. 93:10-16.

4. Steinberg, H.O., H. Chaker, R. Leaming, A. Johnson, G. Brechtel, and A.D. Baron. 1996. Obesity/insulin resistance is associated with endothelial dysfunction. Implications for the syndrome of insulin resistance. J. Clin. Invest. 97: 2601-2610.

5. Mandarino, L.J., A. Consoli, A. Jain, and D.E. Kelley. 1996. Interaction of carbohydrate and fat fuels in human skeletal muscle: impact of obesity and NIDDM. Am. J. Physiol. 270:E463-E470.

6. Scherrer, U., D. Randin, P. Vollenweider, L. Vollenweider, and P. Nicod. 1994. Nitric oxide release accounts for insulin's vascular effects in humans. $J$. Clin. Invest. 94:2511-2515.

7. Steinberg, H.O., G. Brechtel, A. Johnson, N. Fireberg, and A.D. Baron. 1994. Insulin-mediated skeletal muscle vasodilatation is nitric oxide dependent. A novel action of insulin to increase nitric oxide release. J. Clin. Invest. 94: 1172-1179.

8. Baron, A.D., H. Steinberg, G. Brechtel, and A. Johnson. 1994. Skeletal muscle blood flow independently modulates insulin-mediated glucose uptake. Am. J. Physiol. 266:E248-E253.

9. Baron, A.D., H.O. Steinberg, H. Chaker, R. Leaming, A. Johnson, and G. Brechtel. 1995. Insulin-mediated skeletal muscle vasodilatation contributes to both insulin sensitivity and responsiveness in lean humans. J. Clin. Invest. 96: 786-792.

10. Nakane, M., H.H. Schmidt, J.S. Pollock, U. Fostermann, and F. Murad. 1993. Cloned human brain nitric oxide synthase is highly expressed in skeletal muscle. FEBS (Fed. Eur. Biochem. Soc.) Lett. 316:175-180.
11. Balon, T.W., and J.L. Nadler. 1994. Nitric oxide release is present from incubated skeletal muscle preparations. J. Appl. Physiol. 77:2519-2521.

12. Balon, T.W., and J.L. Nadler. 1997. Evidence that nitric oxide increases glucose transport in skeletal muscle. J. Appl. Physiol. 82:359-363.

13. Natali, A., R. Bonadonna, D. Santoro, A.Q. Galvan, S. Baldi, S. Frascerra, C. Palombo, S. Ghione, and E. Ferrannini. 1994. Insulin resistance and vasodilatation in essential hypertension. Studies with adenosine. J. Clin. Invest. 94:1570-1576.

14. Nuutila, P., M. Raitakari, H. Laine, O. Kirvelä, T. Takala, T. Utriainen, S. Mäkimattila, O.P. Pitkänen, U. Ruotsalainen, H. Iida, J. Knuuti, and H. YkiJärvinen. 1996. Role of blood flow in regulating insulin-stimulated glucose uptake in humans. Studies using bradykinin, $\left[{ }^{15} \mathrm{O}\right]$ water, and $\left[{ }^{18} \mathrm{~F}\right]$ fluoro-deoxyglucose and positron emission tomography. J. Clin. Invest. 97:1741-1747.

15. D’Orleans-Juste, P., S. Dion, J. Mizrahi, and D. Regoli. 1985. Effects of peptides and non-peptides on isolated arterial smooth muscles: role of endothelium. Eur. J. Pharmacol. 114:9-21.

16. Cockcroft, J.R., P.J. Chowienczyk, S.E. Brett, and J.M. Ritter. 1994. Effect of $N^{\mathrm{G}}$-monomethy-L-arginine on kinin-induced vasodilatation in the human forearm. Br. J. Clin. Pharmacol. 38:307-310.

17. Shimojo, N., T.G. Pickens, H.S. Margolius, and R.K. Mayfield. 1987. Tissue kallikrein and bradykinin do not have direct insulin-like actions on skeletal muscle glucose utilization. Biol. Chem. Hoppe-Seyler. 368:1355-1361.

18. Rosen, P., J. Eckel, and H. Reinauer. 1983. Influence of bradykinin on glucose uptake and metabolism studied in isolated cardiac myocytes and isolated perfused rat hearts. Hoppe-Seyler's Z Physiol. Chem. 364:1431-1438.

19. Regoli, D., and J. Barabe. 1980. Pharmacology of bradykinin and related kinins. Pharmacol. Rev. 32:1-46.

20. Yki-Järvinen, H., V.A. Koivisto, and S. Karonen. 1985. Influence of body composition on insulin clearance. Clin. Physiol. 5:45-52.

21. Stöcklin, G., V. Pike, C. Crouzel, J. Clark, C. Brihaye, B. Långtröm, C. Lemaire, G. Meyer, B. Nebeling, and S. Stone-Elander, editors. 1993. Radiochemistry automation for PET. In Radiopharmaceuticals for Positron Emission Tomography. Kluwer Academic Publishers, Netherlands. 45-90.

22. Hamacher, K., H.H. Coenen, and G. Stöcklin. 1986. Efficient stereospecific synthesis of no-carrier added $2-\left[{ }^{18} \mathrm{~F}\right]$-fluoro-2-deoxy-D-glucose using aminopolyether supported nucleophilic substitution. J. Nucl. Med. 27:235-238.

23. Iida, H., I. Kanno, S. Miura, M. Murakami, K. Takahashi, and K. Uemura. 1986. Error analysis of a quantitative cerebral blood flow measurement using $\mathrm{H}_{2} 15 \mathrm{O}$ autoradiography and positron emission tomography, with respect to the dispersion of the input function. J. Cereb. Blood Flow Metab. 6:536-545.

24. Nuutila, P., V.A. Koivisto, J. Knuuti, U. Ruotsalainen, M. Teräs, M. Haaparanta, J. Bergman, O. Solin, L. Voipio-Pulkki, U. Wegelius, and H. YkiJärvinen. 1992. Glucose-free fatty acid cycle operates in human heart and skeletal muscle in vivo. J. Clin. Invest. 89:1767-1774.

25. Kety, S.S. 1960. Theory of blood-tissue exchange and its application to measurement of diffusible substance. Methods Med. Res. 8:223-227.

26. Howard, B.E., M.D. Ginserg, W.R. Hassel, A.H. Lockwood, and P. Freed. 1983. On the uniqueness of cerebral blood flow measured by in vivo autoradiography. J. Cereb. Blood Flow Metab. 3:432-441.

27. Ruotsalainen, U., M. Raitakari, P. Nuutila, V. Oikonen, M. Teras, and H. Iida. 1997. Quantitative blood flow measurement of skeletal muscle using 15-oxygen-water and PET. J. Nucl. Med. 38:314-319.

28. Sokoloff, L., M. Reivih, C. Kennedy, M.C. Des Rosiers, C.S. Patlak, K.D. Pettigrew, O. Sakurada, and M. Shinohara. 1977. The $\left[{ }^{14} \mathrm{C}\right]$ deoxy-glucose method for the measurement of local cerebral glucose utilization: theory, procedure and normal values in the conscious and anesthetized albino rats. J. Neurochem. 28:897-916.

29. Patlak, C.S., and R.G. Blasberg. 1985. Graphical evaluation of bloodto-brain transfer constants from multiple-time uptake data: generalizations. $J$. Cereb. Blood Flow Metab. 5:584-590.

30. Gambhir, S.S., M. Schwaiger, S.-C. Huang, J. Krivokavich, H.R. Schelbert, C.A. Nienaber, and M. Phelbs. 1989. A simple non-invasive quantification method for measuring myocardial glucose utilization in humans using positron emission tomography and ${ }^{18} \mathrm{~F}$-deoxyglucose. J. Nucl. Med. 30:359-366.

31. DeFronzo, R.A., J.D. Tobin, and R. Andres. 1979. Glucose clamp technique: a method for quantifying insulin secretion and resistance. Am. J. Physiol. 237:E214-E223.

32. Kadish, A.H., R.L. Little, and J.C. Sternberg. 1968. A new and rapid method for the determination of glucose by measurement of rate of oxygen consumption. Clin. Chem. 14:116-131.

33. Kuzuya, H., P.M. Blix, D.L. Horwitz, D.F. Steiner, and A.H. Rubenstein. 1977. Determination of free and total insulin and C-peptide in insulintreated diabetics. Diabetes. 26:22-29.

34. Lillioja, S., C. Bogardus, D.M. Mott, A.L. Kennedy, W.C. Knowler, and B.V. Howard. 1985. Relationship between insulin-mediated glucose disposal and lipid metabolism in man. J. Clin. Invest. 75:1106-1115.

35. Laakso, M., S.V. Edelman, G. Brechtel, and A.D. Baron. 1990. Decreased effect of insulin to stimulate skeletal muscle blood flow in obese man. $J$. Clin. Invest. 85:1844-1882.

36. Utriainen, T., R. Malmström, S. Mäkimattila, and H. Yki-Järvinen. 1995. Methodological aspects, dose-response characteristics and causes of interindividual variation in insulin stimulation of limb blood flow in normal subjects. 
Diabetologia. 38:555-564.

37. Rabinowitz, D., and K.L. Zierler. 1962. Forearm metabolism in obesity and its response to intra-arterial insulin. Characterization of insulin resistance and evidence for adaptive hyperinsulinism. J. Clin. Invest. 41:2173-2181.

38. Jackson, R.A., N. Peters, U. Advani, G. Perry, J. Rogers, W.H. Brough, and T.R.E. Pilkington. 1973. Forearm glucose uptake during the oral glucose tolerance test in normal subjects. Diabetes. 22:442-458.

39. DeFronzo, R.A., E. Jacot, E. Jequier, E. Maeder, J. Wahren, and J.P. Felber. 1981. The effect of insulin on the disposal of intravenous glucose. Results from indirect calorimetry and hepatic and femoral venous catheterization. Diabetes. 30:1000-1007.

40. DeFronzo, R.A., E. Ferrannini, R. Hendler, P. Felig, and J. Wahren. 1983. Regulation of splanchnic and peripheral glucose uptake by insulin and hyperglycemia in man. Diabetes. 32:34-45.

41. Kelley, D., A. Mitrakou, H. Marsh, F. Schwenck, J. Benn, G. Sonnenberg, M. Arcangeli, T. Aoki, J. Sörensen, M. Berger, P. Sönksen, and J.E. Gerich. 1988. Skeletal muscle glycolysis, oxidation, and storage of an oral glucose load. J. Clin. Invest. 81:1563-1571.

42. Bonadonna, R.C., M.P. Saccomani, L. Seely, K.S. Zych, E. Ferrannini, C. Cobelli, and R.A. DeFronzo. 1993. Glucose transport in human skeletal muscle. The in vivo response to insulin. Diabetes. 42:181-198.

43. Vallance, P., J. Collier, and S. Moncada. 1989. Effects of endotheliumderived nitric oxide on peripheral arteriolar tone in man. Lancet. 2:997-1000.

44. Buchanan, T.A., H. Thawani, W. Kades, J.G. Modrali, F.A. Weaver, C. Laurei, R. Poppiti, A. Xiang, and W. Hsueh. 1993. Angiotensin II increases glucose utilization during acute hyperinsulinemia via a hemodynamic mechanism. J. Clin. Invest. 92:720-726.

45. Jamerson, J.K., S.D. Nesbitt, J.V. Amerena, E. Grant, and S. Julius. 1996. Angiotensin mediates forearm glucose uptake by hemodynamic rather than direct effects. Hypertension. 27:854-858.

46. Madar, Z., J. Zierath, L. Nolte, A. Thorne, H. Voet, and H. WallbergHenriksson. 1997. Human skeletal muscle nitric oxide synthase: characteriza- tion of its activity in obese subjects. Diabetes. 46:24A

47. Yki-Järvinen, H., A.A. Young, C. Lamkin, and J.E. Foley. 1987. Kinetics of glucose disposal in whole body and across the forearm in man. J. Clin. In vest. 79:1713-1719.

48. Dohm, G.L., E.B. Tapscott, W.J. Pories, D.J. Dabbs, E.G. Flickinger, D Meelheim, T. Fushiki, S.M. Atkinson, C.W. Elton, and J.F. Caro. 1988. An in vitro human muscle preparation suitable for metabolic studies. Decreased insulin stimulation of glucose transport in muscle from morbidly obese and diabetic subjects. J. Clin. Invest. 82:486-494.

49. Goodyear, L.J., F. Giorgino, L.A. Sherman, J. Carey, R.J. Smith, and G.L. Dohm. 1995. Insulin receptor phosphorylation, insulin receptor substrate-1 phosphorylation, and phosphatidylinositol 3-kinase activity are decreased in intact skeletal muscle strips from obese subjects. J. Clin. Invest. 95:2195-2204.

50. Dinerman, J.L., C.J. Lowenstein, and S.H. Synder. 1993. Molecular mechanisms of nitric oxide regulation. Potential relevance to cardiovascular disease. Circ. Res. 73:217-222.

51. Welborn, T.A., and K. Wearne. 1979. Coronary heart disease incidence and cardiovascular mortality in Busselton with reference to glucose and insulin concentrations. Diabetes Care. 2:154-160.

52. Pyörälä, K. 1979. Relationship of glucose tolerance and plasma insulin in the incidence of coronary heart disease. Results from two population studies in Finland. Diabetes Care. 2:131-141.

53. Zhang, B., J. Berger, J. Zhou, A. Elbrecht, S. Biswas, S. White-Carrington, D. Szalkowski, and D.E. Moller. 1996. Insulin- and mitogen-activated protein kinase-mediated phosphorylation and activation of peroxisome proliferator-activated receptor gamma. J. Biol. Chem. 271:31771-31774.

54. Nagasaka, Y., K. Kaku, K. Nakamura, and T. Kaneko. 1995. The new oral hypoglycemic agent, CS-045, inhibits the lipid peroxidation of human plasma low density lipoprotein. Biochem. Pharmacol. 50:1109-1111.

55. Noguchi, N., H. Sakai, Y. Kato, J. Tsuchiya, Y. Yamamoto, E. Niki, H. Horikoshi, and T. Kodama. 1996. Inhibition of oxidation of low density lipoprotein by troglitazone. Atherosclerosis. 123:227-234. 